\title{
Tracheobronchial deposition and clearance in small airways in asthmatic subjects
}

\author{
K. Svartengren*, K. Philipson+, M. Svartengren+**, M. Anderson+,**, P. Camner ${ }^{+}$
}

Tracheobronchial deposition and clearance in small airways in asthmatic subjects. $K$. Svartengren, K. Philipson, M. Svartengren, M. Anderson, P. Camner. @ERS Journals Ltd 1996.

ABSTRACT: Asthma tends to impair mucociliary clearance, as assessed from measurements in large airways. However, very little is known about clearance in the smallest airways of the tracheobronchial region.

Deposition and clearance was estimated in 11 subjects with stable asymptomatic asthma and 10 healthy subjects after inhalation of $6 \mu \mathrm{m}$ (aerodynamic diameter) monodisperse Teflon particles labelled with ${ }^{111} \mathrm{In}$. The particles were inhaled at an extremely slow flow, $0.05 \mathrm{~L} \cdot \mathrm{s}^{-1}$. Theoretical calculations and experimental data in healthy subjects using this slow flow support an enhanced deposition in the tracheobronchial region, in particular in the small ciliated airways (bronchioles). Lung retention was measured at $0,24,48$ and $72 \mathrm{~h}$.

Clearance was significant every $24 \mathrm{~h}$ both for asthmatic and healthy subjects, with similar fractions of retained particles at all time-points. The fractions of tracheobronchially-deposited particles were on average 41 and $47 \%$ for asthmatic and healthy subjects, respectively, as compared to a maximal deposition of $30 \%$ using a normal inhalation flow $\left(0.5 \mathrm{~L} \cdot \mathrm{s}^{-1}\right)$. No significant correlation was found between lung retention and lung function, either in asthmatics or in healthy subjects.

Our results indicate that particles clear equally well from small ciliated airways in asthmatic and healthy subjects, maybe as a consequence of an optimal asthma therapy. Furthermore, our results show that it is possible to enhance tracheobronchial deposition both in healthy and asthmatic subjects, i.e. practically independent of airway dimensions, by inhaling rather large aerosol particles extremely slowly. This may be a useful therapeutic approach.

Eur Respir J., 1996, 9, 1123-1129.
*Dept of Respiratory and Allergic Diseases, and **Dept of Medicine, Division of Occupational Medicine, Karolinska Institute, Huddinge University Hospital, Huddinge, Sweden. ${ }^{+}$Division of Inhalation Toxicology, Institute of Environmental Medicine, Karolinska Institute, Stockholm, Sweden.

Correspondence: K. Svartengren Dept of Respiratory and Allergy Diseases M53

Huddinge University Hospital

S-141 86 Huddinge

Sweden

Keywords: Bronchial asthma

lower airways

lung function

particles

Received: April 111995

Accepted after revision February 81996

Supported by grants from the Swedish Asthma and Allergy Association, the Jubilee Fund of Oscar II, and the National Swedish Environmental Protection Board.
Therapeutic aerosols play a prominent role in treating bronchial asthma. An enhanced tracheobronchial deposition of the inhaled aerosols is to be desired and, for some aerosols, for instance corticosteroids, particularly in the small airways. In healthy subjects, a large number of experiments, using different normal inhalation flow rates $\left(0.4-1.2 \mathrm{~L} \cdot \mathrm{s}^{-1}\right)$ and particle sizes $(2.5-16.4 \mu \mathrm{m})$, has given a maximal tracheobronchial deposition of $30 \%$ of all inhaled particles for $6 \mu \mathrm{m}$ particles inhaled at $0.5 \mathrm{~L} \cdot \mathrm{s}^{-1}$ [1]. Similar results have been found by other groups [2]. At a normal inhalation flow, inertial impaction in larger bronchi is the most important mechanism for deposition of particles with an aerodynamic diameter (AD) of $6 \mu \mathrm{m}$. Inhaled at an extremely slow flow, $0.05 \mathrm{~L} \cdot \mathrm{s}^{-1}$, impaction should be insignificant even for these large particles, whereas gravitational sedimentation ought to be marked in small ciliated airways due to the prolonged transit time [3]. This hypothesis was recently tested in healthy subjects [4]. The tracheobronchially deposited fraction of $6 \mu \mathrm{m}$ Teflon particles inhaled at a flow of $0.05 \mathrm{~L} \cdot \mathrm{s}^{-1}$ could be increased to $50 \%$, compared with $30 \%$ inhaled at a flow of $0.5 \mathrm{~L} \cdot \mathrm{s}^{-1}$. In contrast to inhalations of $0.5 \mathrm{~L} \cdot \mathrm{s}^{-1}$, there was a considerable clearance between 24 and $96 \mathrm{~h}$, about $20 \%$ of the total fraction cleared in $96 \mathrm{~h}$, indicating a marked deposition in small ciliated airways. This development gave rise to the unique possibility of investigating clearance in small airways in patients with different airway diseases.

Studies of mucociliary clearance in subjects with bronchial asthma, using radiolabelled test aerosols, indicate that clearance may be only moderately affected. Clearance has been shown to be impaired, as well as enhanced, in asthma-discordant monozygotic twin pairs [5], and patients with chronic stable asthma [6]. In some asthmatics, clearance appears to be normal, at least in large airways [7]. In others, an impaired clearance can be improved, but not fully restored, with systemic corticosteroid treatment [8]. Furthermore, in acute exacerbations of asthma, an impairment seems to be related to the clinical severity of the disease [9]. In these studies, particles larger than $2 \mu \mathrm{m}$ (AD) were used, which means that the particles are deposited mainly in the large airways of the tracheobronchial region and in the alveolar region, but only to a minor extent in the small ciliated airways. Cough clearance can be effective in larger bronchi, where sufficiently high velocities of airflow can be obtained [10], but it might be less effective in smaller bronchi due to the large total cross-sectional area of 
these airways [3]. Thus, in a situation of impaired mucociliary clearance due to airway inflammation, cough may not compensate for the impairment at this level.

The aim of the present study was to investigate tracheobronchial deposition and clearance in small ciliated airways of inhaled $6 \mu \mathrm{m}$ radiolabelled test particles in subjects with asthma, using an extremely slow inhalation flow, $0.05 \mathrm{~L} \cdot \mathrm{s}^{-1}$. We aimed to compare calculated deposition and experimental clearance data with corresponding data for healthy subjects. Finally, lung function was measured for evaluation of relationship with lung deposition. Our hypothesis, assuming that the particles under these conditions deposit similarly in asthmatic and healthy subjects, was that clearance would be impaired in small ciliated airways in asthmatics due to airway inflammation. An impaired clearance in small airways could be of importance for stagnation of secretions and plugging in the acute asthmatic situation and, in the long-term, for the development of irreversible airways obstruction. The other important aspect of the investigation is the therapeutic implication of an enhanced tracheobronchial deposition, in particular in the small airways.

\section{Methods}

\section{Design}

Eleven subjects with asthma and 10 healthy subjects inhaled $6 \mu \mathrm{m}$ (AD) monodisperse Teflon particles labelled with ${ }^{111} \mathrm{In}$. The radioactivity over mouth and throat, lungs and stomach was measured immediately after the inhalation of the test particles. Lung retention was measured at 24, 48 and $72 \mathrm{~h}$. Corrections were made for background radioactivity and physical decay of the radionuclide. Regional deposition was estimated by adjusting the gamma counts registered in the mouth and throat, lungs and stomach to absolute values using factors for self-absorption obtained from measurements in a phantom. The total inhaled activity was obtained by adding the activities from an exhalation filter (Inspiron ${ }^{\circledR}$, C.R. Bard Inc., CA, USA) to the body counts. Immediately before profile scanning, all subjects drank some water to clear particles from the oropharynx and oesophagus. The relationships between lung retentions and lung function parameters reflecting changes in large and small airways were studied. Lung function tests were performed on the same day as exposure to Teflon particles. The present experimental design provides a measure of overall tracheobronchial clearance, i.e. the combined effects of mucociliary clearance and cough.

\section{Subjects}

Eleven subjects with asthma and 10 healthy nonsmoking subjects ( 5 males and 5 females, mean age 29 yrs) volunteered for the study, which was approved by the Ethics Committee on Human Research of the Karolinska Institute. The diagnosis of asthma was based on a typical history of recurrent attacks of reversible dyspnoea with wheezing. Bronchial hyperresponsiveness was confirmed by a histamine inhalation test or a significant reversibility ( $>15 \%$ improvement) on inhaled beta $_{2}-$ agonists. Personal and lung function data in the subjects with asthma are given in tables 1 and 2 . Nine subjects were nonsmokers and two were current smokers. Nine subjects had a history of allergy. Eight subjects used beta $_{2}$-agonists (four inhaled at need, three inhaled regularly, and one used tablets), six inhaled steroids daily, one used oral steroids, and one oral theophylline. All subjects were free from symptoms of asthma and continued their basal treatment, without interruption, during the study period.

\section{Lung function tests}

Forced vital capacity (FVC), forced expiratory volume in one second (FEV1), flow-volume loops (forced expiratory flow at $75-85 \%$ of FVC (FEF75-85\%)), and singlebreath oxygen $\left(\mathrm{SBO}_{2}\right)$ test were measured using a Lung Function Laboratory 2100 (SensorMedics, USA). The manoeuvre of the $\mathrm{SBO}_{2}$ test was a complete exhalation (to residual volume (RV)) followed by a full inhalation (to total lung capacity (TLC)) of $100 \%$ oxygen and, finally,

Table 1. - Personal data in subjects with asthma

\begin{tabular}{|c|c|c|c|c|c|c|c|}
\hline $\begin{array}{l}\text { Subject } \\
\text { No. }\end{array}$ & Sex & $\begin{array}{l}\text { Age } \\
\text { yrs }\end{array}$ & $\begin{array}{l}\text { Height } \\
\mathrm{cm}\end{array}$ & $\begin{array}{c}\text { Weight } \\
\mathrm{kg}\end{array}$ & $\begin{array}{c}\text { Smoking } \\
\text { history }\end{array}$ & $\begin{array}{l}\text { Pack- } \\
\text { years }\end{array}$ & $\begin{array}{c}\text { Duration } \\
\text { of asthma } \\
\text { yrs }\end{array}$ \\
\hline 1 & $\mathrm{~F}$ & 43 & 165 & 87 & Ex-sm & 3.2 & 18 \\
\hline 2 & M & 28 & 168 & 72 & Ex-sm & 1.4 & 4 \\
\hline 3 & M & 32 & 183 & 75 & Ex-sm & 3.0 & 16 \\
\hline 4 & $\mathrm{~F}$ & 28 & 168 & 55 & Never & - & 11 \\
\hline 5 & $\mathrm{M}$ & 39 & 194 & 92 & Ex-sm & 10 & 10 \\
\hline 6 & $\mathrm{~F}$ & 41 & 160 & 59 & Never & - & 21 \\
\hline 7 & $\mathrm{M}$ & 31 & 172 & 88 & Never & - & 31 \\
\hline 8 & $\mathrm{M}$ & 26 & 181 & 72 & Smoker & 8 & 21 \\
\hline 9 & $\mathrm{~F}$ & 30 & 180 & 70 & Smoker & 8 & 21 \\
\hline 10 & $\mathrm{~F}$ & 23 & 158 & 58 & Never & - & 6 \\
\hline 11 & M & 70 & 172 & 80 & Never & - & 70 \\
\hline Mean & & 35 & 173 & 73 & & 5.6 & 21 \\
\hline $\mathrm{SD}$ & & 13 & 11 & 13 & & 3.5 & 18 \\
\hline
\end{tabular}

M: male; F: female; Ex-sm: ex-smoker; Never: lifelong nonsmoker. 
Table 2. - Lung function data in subjects with asthma

\begin{tabular}{|c|c|c|c|c|c|c|c|}
\hline \multirow{2}{*}{$\begin{array}{l}\text { Subject } \\
\text { No. }\end{array}$} & \multirow{2}{*}{$\begin{array}{c}R \text { aw } \\
\mathrm{kPa} \cdot \mathrm{L}^{-1} \cdot \mathrm{s}\end{array}$} & \multicolumn{2}{|c|}{ FEV1 } & \multicolumn{2}{|c|}{ FVC } & \multirow{2}{*}{$\begin{array}{l}\mathrm{FEF} 75-85 \% \\
\mathrm{~L} \cdot \mathrm{s}^{-1}\end{array}$} & \multirow{2}{*}{$\begin{array}{c}\mathrm{N}_{2} \text {-delta } \\
\% \cdot \mathrm{L}^{-1}\end{array}$} \\
\hline & & $\mathrm{L}$ & $\%$ pred $*$ & $\mathrm{~L}$ & $\%$ pred* & & \\
\hline 1 & 0.249 & 2.50 & 88 & 3.00 & 91 & 0.68 & 1.2 \\
\hline 2 & 0.093 & 4.37 & 112 & 5.33 & 116 & 1.21 & 0.6 \\
\hline 3 & 0.198 & 2.73 & 61 & 5.47 & 102 & 0.36 & 2.1 \\
\hline 4 & 0.282 & 3.01 & 91 & 4.00 & 105 & 0.76 & 0.6 \\
\hline 5 & 0.126 & 4.77 & 102 & 6.31 & 110 & 0.83 & 1.3 \\
\hline 6 & 0.196 & 2.74 & 102 & 3.73 & 119 & 0.33 & 0.9 \\
\hline 7 & 0.242 & 3.63 & 90 & 5.07 & 106 & 0.68 & 1.0 \\
\hline 8 & 0.114 & 4.69 & 104 & 6.06 & 113 & 1.24 & 1.0 \\
\hline 9 & 0.123 & 3.64 & 96 & 4.59 & 106 & 0.91 & 0.7 \\
\hline 10 & 0.218 & 2.69 & 90 & 3.35 & 98 & 0.84 & 0.6 \\
\hline 11 & 0.400 & 1.23 & 42 & 2.29 & 61 & 0.19 & 5.5 \\
\hline Mean & 0.200 & 3.27 & 89 & 4.47 & 102 & 0.73 & 1.4 \\
\hline $\mathrm{SD}$ & 0.090 & 1.07 & 20 & 1.30 & 16 & 0.34 & 1.4 \\
\hline
\end{tabular}

*: predicted values according to QUANJER [11]. Raw: airway resistance; FEV1: forced expiratory volume in one second; FVC: forced vital capacity; \% pred: percentage of predicted value; FEF75-85\%: forced expiratory flow at $75-85 \%$ of FVC; $\mathrm{N}_{2}$-delta: slope of phase III calculated as mean of at least two tests.

a complete exhalation, with a flow of $0.3-0.6 \mathrm{~L} \cdot \mathrm{s}^{-1}$. During the exhalation, the $\mathrm{N}_{2}$ concentration in the exhaled air was continuously measured. The slope of phase III, given as $\mathrm{N}_{2}$-delta, was calculated as the mean of at least two tests. The subjects wore a noseclip and were in a sitting position. Airway resistance (Raw), and thoracic gas volume (TGV) were measured using a panting technique within a whole-body plethysmograph (Transmural Body Box 2800; SensorMedics, USA). All lung function parameters were determined according to the criteria proposed by QuANJER [11].

\section{Clearance measurements}

Production and inhalation of the test particles. The Teflon particles were produced and labelled with ${ }^{111}$ In (half-life $68 \mathrm{~h}$ ) by a spinning disc technique $[12,13]$. The mean geometric particle diameter was $4.0 \mu \mathrm{m}$, estimated by measurements in a light microscope (Visopan projection microscope; Reichert, Austria). The coefficient of variation was $7 \%$. From the density of the Teflon particles $\left(2.13 \mathrm{~g} \cdot \mathrm{cm}^{-3}\right)$ the mean $\mathrm{A} \Delta$ was calculated to be 5.8 $\mathrm{um}$. The particles were made wet and well-dispersed by the addition of $0.2 \%$ tergitol solution. Before aerosolization, they were washed in water at $37^{\circ} \mathrm{C}$ and the leakage of radioactivity of the washed particles was $<1 \%$ per day. The particles were suspended in water $(3.0 \mathrm{mg}$ particles $\cdot \mathrm{mL}^{-1}$ ) and $0.3 \mathrm{~mL}$ of the suspension was sprayed up 2-3 times into a $25 \mathrm{~L}$ glass bulb with a Beckman Atomizer. Before inhalation started, it was ascertained that there was no visible mist. If necessary, dry air was passed into the bulb. The subjects wore a noseclip and inhaled the particles in a sitting position with 8-12 deep inhalations at a flow of $0.05 \mathrm{~L} \cdot \mathrm{s}^{-1}$. Each inhalation lasted about $20 \mathrm{~s}$, during which time all particles deposited by means of sedimentation. The exposure time was 8-12 min. In order to facilitate the maintenance of such a slow flow, a resistance to airflow was inserted into the ambient air inlet of the glass bulb. It was shaped as a 3 $\mathrm{mm}$ long channel with a diameter of $1.8 \mathrm{~mm}$. The flow was measured with a pneumotachograph, positioned between the bulb and the mouthpiece, and was recorded graphically. By looking at the recorder needle, the subjects could inhale at a fairly constant rate throughout the inspiration. All subjects were trained to inhale in this manner before they inhaled the test particles. During the first $7 \mathrm{~min}$ of each exposure, the inhalation flow was recorded by a computer with a sample frequency of $10 \mathrm{~Hz}$, and the mean \pm sD for each breath during this period was calculated. All exhalations during exposure were performed through a low-resistance filter. The proportion of exhaled particles was at most $1-2 \%$ of the inhaled radioactivity. The radioactivity deposited in the lungs was about $0.1 \mathrm{MBq}$.

Measurement of radioactivity. Radioactivity was measured using two $13 \times 5 \mathrm{~cm} \mathrm{NaI}$ crystals fitted with collimators [12]. Profile scanning over mouth and throat, lungs and stomach of the supine subject was performed twice immediately after inhalation. Radioactivity was also measured over the lungs 24, 48 and $72 \mathrm{~h}$ later. The counts from the two detectors were measured and recorded separately to permit discrimination between the activities in the lungs and stomach. Radioactivity in exhalation filters was also measured using the profile scanner. Factors for self-absorption of radioactivity in head and throat, lungs and stomach were 2, 2.5 and 4, respectively. These factors were obtained from measurements using an Alderson Rando Phantom [14].

\section{Theoretical calculations of lung deposition}

Theoretical deposition data as a function of $R$ aw were examined using a computer-based lung model. The model is based on the equations for impaction and sedimentation adopted by the Task Group on Lung Dynamics [15], and on the human airway model "A" (comprising generations 0 to 23 in a lung volume of $4,800 \mathrm{~mL}$ ) proposed by WeIBEL [3]. In the model, several inhalation parameters can be changed within a wide range (airway dimensions, tidal volume, inspiratory flow, postinspiratory pause, and expiratory time), and both the geometric diameter 
of the particles and the particle density can be altered. The diameters of generations 4 to 23 were changed by the same factor and deposition for each generation for the average $R$ aw found for healthy subjects and subjects with asthma was calculated. The dimension factors 0.8 for healthy subjects and 0.55 for asthmatics were used, together with a tidal volume of $1,800 \mathrm{~mL}$, and a pause of $2 \mathrm{~s}$. A constant of $0.5 \mathrm{cmH}_{2} \mathrm{O} \cdot \mathrm{L}^{-1} \cdot \mathrm{s}$ was added on account of $R$ aw in mouth and throat, and larynx [16].

\section{Statistical analysis}

Student's t-test was used to compare differences in lung retention over time. Linear regression analysis was used for evaluation of correlations between lung retentions and lung function parameters. The level of significance was 0.05 .

\section{Results}

\section{Clearance measurements}

The mean inhalation flow rates were $0.04 \pm 0.003 \mathrm{~L} \cdot \mathrm{s}^{-1}$ (mean \pm SD) and $0.04 \pm 0.004 \mathrm{~L} \cdot \mathrm{s}^{-1}$ in the asthmatic and healthy subjects, respectively. These values were calculated from the mean flow of all inspirations completed during the first $420 \mathrm{~s}$ of each exposure recorded. The mean inhalation flow $\left(0.04 \mathrm{~L} \cdot \mathrm{s}^{-1}\right)$ was, thus, somewhat lower than the intended $0.05 \mathrm{~L} \cdot \mathrm{s}^{-1}$.

Deposition in the mouth and throat, and in the lung, and lung retention at 24 (Ret24), $48(\operatorname{Ret} 48)$ and $72 \mathrm{~h}$ (Ret72) in the asthmatics are presented in table 3, and in the healthy subjects in table 4. Mouth and throat deposition, estimated from the measured activities over mouth and throat, and stomach immediately after the inhalation

Table 3. - Deposition in the mouth and throat, and lung in 11 asthmatics immediately after inhalation of the particles, lung retention at 24 (Ret24), 48 (Ret48) and 72 h (Ret72), and tracheobronchial deposition

\begin{tabular}{|c|c|c|c|c|c|c|}
\hline $\begin{array}{l}\text { Subject } \\
\text { No. }\end{array}$ & $\begin{array}{l}\text { Mouth and throat } \\
\text { deposition* }\end{array}$ & $\underset{\text { deposition* }}{\text { Lung }}$ & $\underset{\%}{\operatorname{Ret} 24^{\#}}$ & $\begin{array}{c}\operatorname{Ret} 48^{\#} \\
\%\end{array}$ & $\begin{array}{c}\operatorname{Ret} 72^{\#} \\
\%\end{array}$ & $\begin{array}{c}\text { Tracheobronchial } \\
\text { deposition } \ddagger \\
\%\end{array}$ \\
\hline 1 & 22 & 78 & 52 & 41 & 36 & 50 \\
\hline 2 & 30 & 70 & 57 & 47 & 47 & 37 \\
\hline 3 & 36 & 64 & 57 & 55 & 58 & 27 \\
\hline 4 & 22 & 78 & 59 & 60 & 54 & 36 \\
\hline 5 & 24 & 76 & 56 & 58 & 53 & 36 \\
\hline 6 & 53 & 47 & 62 & 47 & 42 & 27 \\
\hline 7 & 24 & 76 & 45 & 42 & 31 & 52 \\
\hline 8 & 19 & 81 & 49 & 46 & 36 & 52 \\
\hline 9 & 22 & 78 & 53 & 53 & 40 & 47 \\
\hline 10 & 25 & 75 & 55 & 46 & 35 & 49 \\
\hline 11 & 17 & 83 & 58 & 51 & 47 & 44 \\
\hline Mean & 27 & 73 & 55 & 50 & 43 & 41 \\
\hline SD & 10 & 10 & 5 & 6 & 9 & 9 \\
\hline
\end{tabular}

*: deposition in percentage of inhaled particles; \#: retained particles at 24,48 and $72 \mathrm{~h}$ in percentage of the initial amount of lung deposition; $¥:$ tracheobronchial deposition in percentage of all inhaled particles.

Table 4. - Deposition in the mouth and throat, and lung in 10 healthy subjects immediately after inhalation of the particles, lung retention at 24 (Ret24), 48 (Ret48) and $72 \mathrm{~h}$ (Ret72), and tracheobronchial deposition

\begin{tabular}{lcccccc}
\hline $\begin{array}{l}\text { Subject } \\
\text { No. }\end{array}$ & $\begin{array}{c}\text { Mouth and throat } \\
\text { deposition* }\end{array}$ & $\begin{array}{c}\text { Lung } \\
\text { deposition* }\end{array}$ & $\begin{array}{c}\text { Ret24 } \\
\%\end{array}$ & $\begin{array}{c}\text { Ret48 } \\
\%\end{array}$ & $\begin{array}{c}\text { Ret72 } \\
\%\end{array}$ & $\begin{array}{c}\text { Tracheobronchial } \\
\text { deposition } \\
\%\end{array}$ \\
\hline 1 & 30 & 70 & 49 & 38 & 35 & 45 \\
2 & 24 & 76 & 54 & 45 & 41 & 45 \\
3 & 27 & 73 & 58 & 50 & 44 & 41 \\
4 & 23 & 77 & 51 & 45 & 37 & 49 \\
5 & 19 & 81 & 44 & 38 & 33 & 54 \\
6 & 8 & 92 & 45 & 36 & 29 & 65 \\
7 & 14 & 86 & 53 & 35 & 36 & 53 \\
8 & 21 & 79 & 64 & 56 & 52 & 39 \\
9 & 33 & 67 & 52 & 45 & 42 & 43 \\
10 & 22 & 78 & 52 & 49 & 45 & 47 \\
\hline Mean & 22 & 78 & 52 & 44 & 39 & 7 \\
SD & 7 & 7 & 6 & 7 & & 8 \\
\hline
\end{tabular}

*: deposition in percentage of inhaled particles; \#: retained particles at 24, 48 and $72 \mathrm{~h}$ in percentage of the initial amount of lung deposition; ‡: tracheobronchial deposition in percentage of all inhaled particles. 


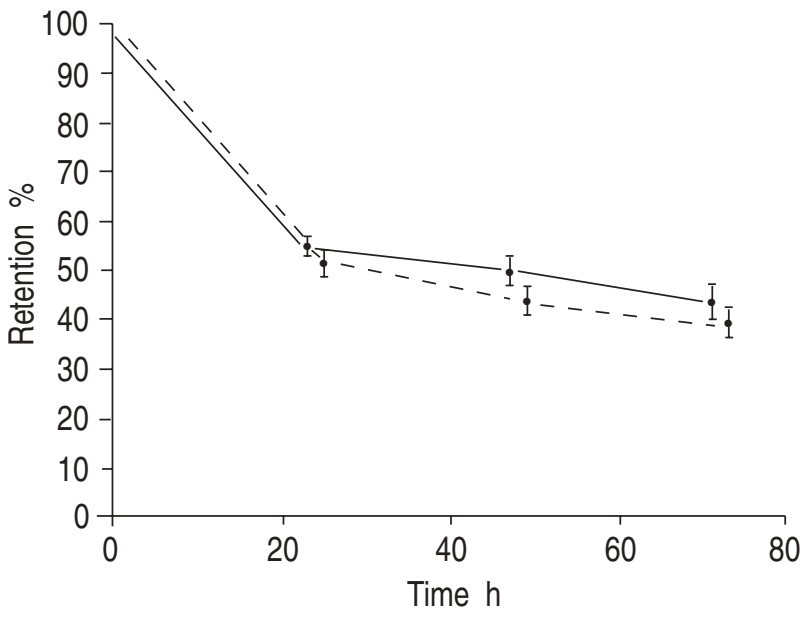

Fig. 1. - The average retentions of $6 \mu \mathrm{m}(\mathrm{AD})$ particles in 11 subjects with asthma and 10 healthy subjects when the particles are inhaled at an extremely slow flow, $0.05 \mathrm{~L} \cdot \mathrm{s}^{-1}$. Values are presented as mean \pm SEM. AD: aerodynamic diameter. $\_$: subjects with asthma; -..-.-.-.: healthy subjects.

of the test particles, ranged $8-53 \%$, with mean values of 27 and $22 \%$ in the asthmatic and healthy subjects, respectively. There was no significant difference between these values. In figure 1 , the average lung retentions for the asthmatic subjects are compared with the average retentions for the healthy subjects. Clearance was significant between 0 and 24, 24 and 48, and 48 and $72 \mathrm{~h}$ ( $\mathrm{p}<0.05$, two-tailed paired t-test) both for asthmatic and healthy subjects. The asthmatics cleared $22 \%$ of the retained fraction available at $24 \mathrm{~h}$, and the healthy subjects correspondingly cleared $25 \%$. There was no significant $(\mathrm{p}>0.05)$ difference in retained fractions over time between the asthmatic and healthy subjects.

No significant correlation was found between lung function parameters and lung retentions (Ret24-72), in large (Raw), or in small airways (FEF75-85\% and $\mathrm{N}_{2}-$ delta), either in asthmatics or in healthy subjects. In the healthy subjects, $R$ aw ranged $0.07-0.16 \mathrm{kPa} \cdot \mathrm{L}^{-1} \cdot \mathrm{s}$ (mean $\pm \mathrm{SD}$ $\left.0.11 \pm 0.03 \mathrm{kPa} \cdot \mathrm{L}^{-1} \cdot \mathrm{s}\right), \mathrm{FEF} 75-85 \% 0.4-2.4 \mathrm{~L} \cdot \mathrm{s}^{-1}($ mean $\pm \mathrm{SD}$ $\left.1.5 \pm 0.6 \mathrm{~L} \cdot \mathrm{s}^{-1}\right)$, and $\mathrm{N}_{2}$-delta $0.5-1.5 \% \cdot \mathrm{L}^{-1}($ mean $\pm \mathrm{SD}$ $\left.0.9 \pm 0.3 \% \cdot \mathrm{L}^{-1}\right)$.

The tracheobronchially deposited fractions, in percentage of all inhaled particles, were $41 \pm 9 \%$ (mean \pm SD) and $47 \pm 8 \%$ for the asthmatic and healthy subjects, respectively (tables 3 and 4). These values were estimates based on the fractions retained at $72 \mathrm{~h}$. Table 3 shows the similarity in tracheobronchial deposition among the asthmatics, even for those with the most impaired lung function values (Nos. 3 and 11).

\section{Theoretical calculations}

According to theoretical calculations, inhalations at a normal flow $\left(0.5 \mathrm{~L} \cdot \mathrm{s}^{-1}\right)$ will favour deposition in the large airways of the tracheobronchial region, as well as in the alveolar region, and only very small amounts will deposit in the small conducting airways (in generations 12 to 16: $10-15 \%)$. Theoretical calculations of inhalations at an extremely slow flow $\left(0.05 \mathrm{~L} \cdot \mathrm{s}^{-1}\right)$ show a completely different deposition pattern. Practically all particles are deposited by means of gravitational sedimentation during inhalation. The main fraction is deposited in the a) Healthy subjects

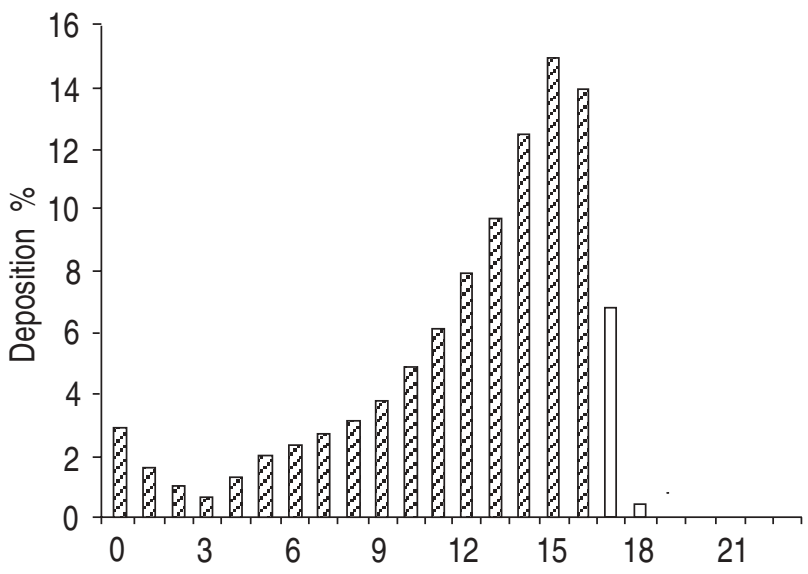

b) Asthmatics

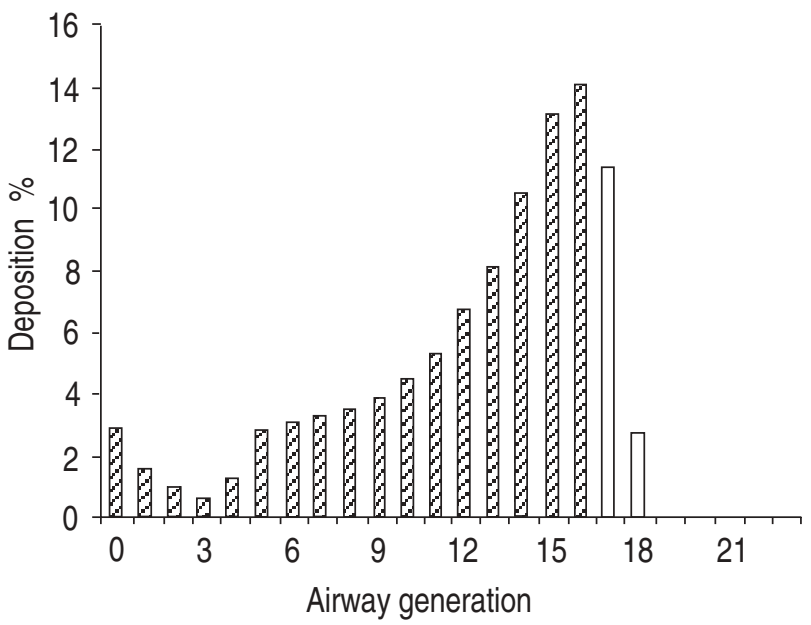

Fig. 2. - Theoretical deposition data on $6 \mu \mathrm{m}$ (AD) particles inhaled with a tidal volume of $1,800 \mathrm{~mL}$ at $0.05 \mathrm{~L} \cdot \mathrm{s}^{-1}$. Deposition calculated for: a) healthy subjects; and b) subjects with asthma, using the airway model proposed by Weibel [3], comprising the conductive (generations $0-16$, hatched columns) and respiratory zones (generations 17-23, open columns). AD: aerodynamic diameter.

small conducting airways (in generations 12 to 16 : 50$60 \%$ ), i.e. in the bronchiolar region, practically independent of the degree of constriction and dilation of large and small bronchi. Deposition due to inertial impaction in large airways is insignifcant, as is the penetration into the alveoli. Calculations for healthy subjects and subjects with asthma showed similar deposition patterns, with only 13 and $7 \%$ of the particles deposited in the alveolar region (generations 17 to 23) in the asthmatic and healthy subjects, respectively (fig. 2).

\section{Discussion}

Deposition in the mouth and throat of slowly inhaled $6 \mu \mathrm{m}$ particles was on average 27 and $22 \%$ for asthmatic and healthy subjects, respectively. These values agree with those recently found for healthy subjects [4], and are considerably lower than the $40 \%$ obtained with a normal flow [1], most probably due to a lower degree of impaction. 
At a normal inhalational flow, $6 \mu \mathrm{m}$ particles deposit mainly in the large airways of the tracheobronchial region. The fractions of cleared particles from these airways are larger for subjects with asthma, as compared to healthy subjects, due to a more central deposition in obstructed airways [17]. In the present study, we intended to selectively deposit particles in the smallest ciliated airways. This was recently successfully carried out in healthy subjects by using inhalations at an extremely slow flow [4]. The tracheobronchially deposited fraction could be increased by $70 \%$, compared with inhalations using a normal flow. Furthermore, compared with normal inhalations, a different clearance pattern was obtained, with an intermediate phase of continued clearance between 24 and $96 \mathrm{~h}$, assumed to represent clearance from the bronchiolar region.

Similar fractions of retained particles were found, measured over $72 \mathrm{~h}$, in the asthmatic and healthy subjects when the particles were inhaled extremely slowly. If it is assumed that deposition is similar between healthy and asthmatic subjects, this indicates an unaffected overall bronchiolar clearance in the asthmatics. It is assumed that the fractions cleared between 24 and $72 \mathrm{~h}$ reflect clearance from the smallest ciliated airways, since alveolar clearance of Teflon particles during this time period is insignificant $[17,18]$, as is the leakage of radioactivity of the particles. In the present study, the asthmatic subjects did not interrupt their medical treatment, nor did they suffer from symptoms of their disease at the time of the investigation. Thus, one interpretation of our results may be that the asthmatics were under optimal treatment with anti-inflammatory drugs. This is compatible with results of recent studies, which have shown that longterm treatment with inhaled anti-inflammatory drugs can fully restore the airway epithelium in mild asthma [19].

The antiasthma medication may have affected deposition and mucociliary clearance rates. At normal flow rates, airway resistance predicts deposition [20-22]. However, in the present study, at the extremely slow inhalation flow used, deposition was rather insensitive to changes in airway dimensions, as judged by theoretical calculations and the lack of correlation between airway resistance and lung retention (see below). We cannot exclude that a possible stimulating effect of medication on mucociliary transport may have improved an impaired overall bronchiolar clearance. Beta ${ }_{2}$-agonists and theophylline are known to directly stimulate mucociliary clearance, but recent studies in healthy subjects suggest that the acute increase in mucociliary clearance rates caused by these drugs is not sustained over time [23]. Corticosteroids may affect clearance rates by reducing airway inflammation [8, 19].

We calculated lung deposition for $6 \mu \mathrm{m}$ (AD) particles inhaled at $0.05 \mathrm{~L} \cdot \mathrm{s}^{-1}$. According to these calculations, only 13 and $7 \%$ of the particles were deposited in the alveolar region in the asthmatic and healthy subjects, respectively. These calculated values are markedly lower than the retention values obtained experimentally (fig. 1). The most probable explanation is a significant retention of particles in the smallest ciliated airways of the tracheobronchial region, for instance in generations 12 to 16 (fig. 2). Very little is known about clearance from the bronchiolar region in humans [24]. This region constitutes a transitional zone, between the tracheobronchial and alveolar regions. Tracheobronchial as well as alveolar clearance mechanisms may be involved and give rise to intermediate clearance rates.

Studies on particles inhaled by bolus technique also suggest that there may be a substantial fraction of particles deposited in the tracheobronchial region that does not clear within days in healthy subjects [25]. A reasonable explanation of these results would be a considerable deposition of bolus particles in the bronchiolar region. This is supported by the fact that the clearance patterns in healthy subjects are similar for particles inhaled in boli, or inhaled at $0.05 \mathrm{~L} \cdot \mathrm{s}^{-1}[4,25]$. Another explanation of the large retentions, obtained by both these inhalation techniques, is that the particles have after all penetrated into the alveoli. However, for inhalations of $0.05 \mathrm{~L} \cdot \mathrm{s}^{-1}$, this seems improbable considering theoretical calculations.

It has been proposed that an enhanced deposition of therapeutic aerosols in the peripheral airways would be of value, particularly with regard to treatment with inhaled corticosteroids. This might be even more true in the treatment of diseases with early inflammation of small airways, such as in chronic bronchitis [26, 27], and nonfatal asthma [28]. The present study presents a method of enhancing deposition in these airways in patients with mild airways obstruction, practically independent of airway resistance. If an enhanced deposition in the small airways should be considered important in any treatment, extremely slow inhalation of aerosols composed of rather large particles might provide a possible approach.

We have previously found significant correlations between lung retentions and lung function parameters for different pulmonary diseases using a normal inhalational flow. Lung retentions were, for instance, correlated with $R$ aw in healthy subjects [20] and patients with chronic bronchitis [29], and with Raw, FEF75-85\% and $\mathrm{N}_{2}$-delta in patients with asthma $[17,21]$ and immotile cilia syndrome [22]. The correlation between retained fractions and airway resistance ( $R$ aw) was negative, i.e. the more obstructed the airways, the smaller were the retained fractions. In the present study, using an extremely slow inhalation flow, we found no relationship between lung retentions and the lung function parameters Raw, FEF75-85\% and $\mathrm{N}_{2}$-delta. This was in accordance with theoretical calculations and supports the independence of deposition of airway dimensions. An uneven ventilation in asthma would tend to increase the amount of particles reaching the alveoli, as a consequence of a shorter transit time due to the reduced total cross-sectional area. This could result in larger lung retentions in asthmatics compared with healthy subjects. However, we found no correlation between lung retentions and lung function measures reflecting uneven ventilation $\left(\mathrm{N}_{2}\right.$-delta), as would have been expected. Thus, we found no support for an uneven ventilation affecting deposition of relatively large particles inhaled extremely slowly.

Estimating the tracheobronchially deposited fraction at $72 \mathrm{~h}$ is handicapped by uncertainty in knowing whether the test particles are entirely, or partially, deposited in the small ciliated airways. If the particles, at $72 \mathrm{~h}$, were retained mainly in the small ciliated airways and not in the alveoli, our data on tracheobronchial deposition are underestimations.

In conclusion, this study shows that particles clear 
equally well from small ciliated airways in asthmatic and healthy subjects, possibly as a consequence of an optimal asthma therapy. This finding indicates that overall clearance from the bronchiolar region is not predominantly affected in mild-to-moderate asthma. Furthermore, our results show that the tracheobronchially deposited fraction of inhaled particles can be enhanced by inhaling relatively large aerosol particles extremely slowly, and that the deposition pattern is independent of airway dimensions. This approach may be of therapeutic importance, in particular in the treatment of patients with obstructive airway diseases.

Acknowledgements: The authors thank K. WidtskiöldOlsson, L. Persson, and U. Bergsten for expert technical assistance.

\section{References}

1. Anderson M, Svartengren M, Dahlbäck M, Nerbrink O, Philipson K, Camner P. Human tracheobronchial deposition and effect of two cholinergic aerosols. Exp Lung Res 1993; 19: 653-669.

2. Stahlhofen W, Rudolf G, James AC. Intercomparison of experimental regional aerosol deposition data. J Aerosol Med 1989; 2: 285-308.

3. Weibel ER. In: Morphometry of the human lung. New York, Springer-Verlag, Berlin Academic Press, 1963; pp. 136-143.

4. Anderson M, Philipson K, Svartengren M, Camner P. Human deposition and clearance of $6 \mu \mathrm{m}$ particles inhaled with an extremely low flow rate. Exp Lung Res 1995; 21: $187-195$.

5. Svartengren M, Ericsson CH, Philipson K, Mossberg B, Camner P. Tracheobronchial clearance in asthmadiscordant monozygotic twins. Respiration 1989; 56: 70-79.

6. O'Riordan TG, Zwang J, Smaldone GC. Mucociliary clearance in adult asthma. Am Rev Respir Dis 1992; 146: 598-603.

7. Mossberg B, Strandberg K, Philipson K, Camner P. Tracheobronchial clearance in bronchial asthma: response to beta-adrenoceptor stimulation. Scand J Respir Dis 1976; 57: 119-128.

8. Agnew JE, Bateman JRM, Sheahan NF, Lennard-Jones AM, Pavia D, Clarke SW. Effect of oral corticosteroids on mucus clearance by cough and mucociliary transport in stable asthma. Bull Eur Physiopathol Respir 1983; 19: 37-41.

9. Messina M, O'Riordan T, Smaldone G. Changes in mucociliary clearance during acute exacerbations of asthma. Am Rev Respir Dis 1991; 143: 993-997.

10. Leith DE. Cough. Phys Ther 1968; 48: 439-447.

11. Quanjer PH, ed. Standardized lung function testing. Report Working Party "Standardization of Lung Function Tests". European Coal and Steel Community. Bull Eur Physiopathol Respir 1983; 19(5): 7-10.

12. Camner P. The production and use of test aerosols for studies of human tracheobronchial clearance. Environ Physiol Biochem 1971; 1: 137-154.

13. Philipson K. Monodisperse labelled aerosols for studies of lung clearance. In: Abstracts of Uppsala. Dissertations from the Faculty of Science. Uppsala, Sweden, 1977; 433: $1-36$.

14. Svartengren M, Falk R, Linnman L, Philipson K, Camner P. Deposition of large particles in human lung. Exp Lung Res 1987; 12: 75-88.

15. Task Group on Lung Dynamics. Deposition and retention models for internal dosimetry of the human respiratory tract. Health Phys 1966; 12: 173-207.

16. Hyatt RE, Wilcox RE. Extrathoracic airway resistance in man. J Appl Physiol 1961; 16: 326-330.

17. Svartengren M, Anderson M, Bylin G, Philipson K, Camner P. Regional deposition of $3.6 \mu \mathrm{m}$ particles in subjects with mild to moderately severe asthma. J Aerosol Med 1990; 3: 197-207.

18. Camner P, Philipson K. Human alveolar deposition of $4 \mu \mathrm{m}$ Teflon particles. Arch Environ Health 1978; 33 : $181-185$.

19. Laitinen LA, Laitinen A, Haahtela T. A comparative study of the effects of an inhaled corticosteroid, budesonide, and a beta ${ }_{2}$-agonist, terbutaline, on airway inflammation in newly diagnosed asthma: a randomized double-blind, parallel-group controlled trial. J Allergy Clin Immunol 1992; 90: 32-42.

20. Svartengren M, Philipson K, Linnman L, Camner P. Airway resistance and deposition of particles in the lung. Exp Lung Res 1984; 7: 257-269.

21. Svartengren M, Anderson M, Bylin G, Philipson K, Camner P. Regional deposition of $3.6 \mu \mathrm{m}$ particles and lung function in asthmatic subjects. J Appl Physiol 1991; 71(6): 2238-2243.

22. Ruusa J, Svartengren M, Philipson K, Camner P. Tracheobronchial particle deposition and clearance in immotile cilia syndrome patients. J Aerosol Med 1993; 6: 89-98.

23. Perry RJ, Smaldone GC. Effect of bronchodilators on mucociliary clearance in normal adults. $J$ Aerosol Med 1990; 3: 187-196.

24. ICRP (International Commission on Radiological Protection). Human respiratory tract model for radiological protection. ICRP Publication 66 Ann ICRP 24: 1-3, Oxford, Elsevier Science Ltd, 1994.

25. Scheuch G, Philipson K, Falk R, et al. Retention of particles inhaled in boli with and without induced bronchoconstriction. Exp Lung Res 1995; 21: 901-916.

26. Ebert RV, Terracio MJ. The bronchiolar epithelium in cigarette smokers: observations with the scanning electron microscope. Am Rev Respir Dis 1975; 111: 4-11.

27. Cosio M, Ghezzo H, Hogg JC, et al. The relations between structural changes in small airways and pulmonary function tests. N Engl J Med 1977; 298: 1277-1281.

28. Green FHY, Harji S, Butt JC, et al. Regional distribution of airway smooth muscle in asthma. J Aerosol Med 1995; 8(1): 94.

29. Ericsson $\mathrm{CH}$, Svartengren K, et al. Repeatability of airway deposition and tracheobronchial clearance rate over three days in chronic bronchitis. Eur Respir J 1995; 8: $1886-1893$. 